\title{
La construcción de la persona inmigrante en el limbo jurídico: ni expulsables ni regularizables en España
}

\author{
Adriana Jarrín Morán
}

resumen $\mathrm{El}$ objetivo del estudio es reflexionar sobre la forma en que han sido afectadas las vidas de los inmigrantes en situación irregular que, debido a una paradoja de la Ley de Extranjería de España, no son ni expulsables ni regularizables. La metodología que guió el trabajo fue la investigación etnográfica que, a través del análisis concreto de los inmigrantes en "limbo jurídico", ha permitido articular el alcance de las políticas migratorias en la construcción de la persona inmigrante, exponer la forma en que las leyes condicionan la vida de los inmigrantes y dimensionar cómo la restricción de los derechos ciudadanos deviene en un proceso de despersonalización social y jurídico de los inmigrantes en situación irregular. Los ejes temáticos son: a) Políticas migratorias: legislaciones excluyentes; b) Centros de Internamiento de Extranjeros: ruptura de la regularidad de la irregularidad; c) La construcción de la persona inmigrante en el limbo jurídico. O objetivo deste estudo é refletir sobre a forma como tem sido afetada a vida de imigrantes em situação irregular que, devido a um paradoxo na Lei de Imigraçáo da Espanha, não podem ser deportados nem regularizados.

palabras clave Políticas migratorias. "Limbo jurídico”. CIEs. Persona no-persona. Exclusión..

\section{Introducción}

Los movimientos migratorios constituyen, actualmente, uno de los principales fenómenos a nivel global debido a su expansión y acelerado crecimiento que está provocando la transformación de las estructuras sociales, económicas y políticas tanto de los países de origen como de destino. Las migraciones internacionales se presenta como un nuevo status quo de la población mundial que se encuentra en constante movimiento o que, directa o indirectamente, participa de las redes y cadenas migratorias transnacionales (De Lucas, 1994).

La principal causa para la emigración responde a condiciones económicas, sin embargo, existen otras motivaciones que, conjuntamente con los efectos del sistema económico, diversifican el abanico de factores que provocan la emigración de las poblaciones, especialmente de aquellas que tienen como destino a Europa: la desertización del norte de África, la intensificación de los conflictos políticos y armados en países africanos y de Europa del Este, la especialización académica y científica, la elección de país de residencia, etc. (Bodei, 2002 [1999]; Rodríguez, 2010).

En la última década, el incremento de las emigraciones de la población procedente de países de economías débiles hacia países europeos responde prioritariamente al impacto que ha tenido la implementación del modelo neoliberal en sus sistemas económicos y sociales, lo que ha traído como consecuencia la agudización de la pobreza, forzando a las personas a su desplazamiento en búsqueda de mejores alternativas de vida (Castles y Miller, 2009 [1993]). Simultáneamente, los procesos de globalización han promovido la intensificación del flujo 
de información, facilitando la creación de redes transnacionales sociales, familiares y políticas, que han provocado el efecto "llamada" por parte de personas migradas establecidas en países europeos hacia sus connacionales en los países de origen (Pedone, 2010).

Europa, por su parte, y España en especial, abrieron las puertas a la población procedente de los países del sur como una alternativa temporal para cubrir las necesidades del mercado laboral en sectores no cualificados como la agricultura, el servicio doméstico y la construcción, que contaban con plazas vacantes debido a la precariedad salarial, a la profesionalización de la población europea y al crecimiento de las urbes, respectivamente. Los inmigrantes fueron acogidos como mano de obra barata y con derechos laborales restringidos (De Lucas, 1994).

En este sentido, existe una vinculación directa entre los factores que motivan la emigración y que fomentan la inmigración, la correlación de fuerzas provocadas por el mercado determinó las condiciones, temporales y espaciales, para la existencia de un excedente de población forzada a salir de sus países de origen y a la recepción de esa población en un mercado laboral precarizado. Como señala Gil Araujo: "La relación intrínseca entre emigrante/inmigrante, obliga también a la tarea de escudriñar la recíproca relación (siempre desigual) entre las sociedades de emigración y las sociedades de inmigración" (2008, p. 243).

Ante la escalada del flujo migratorio, la Unión Europea estableció un sistema de cupos para regular la entrada de inmigrantes en base a las exigencias del mercado laboral (Delgado, 2002), sin embargo, el sistema de cupos fue insuficiente no sólo ante la inmensa cantidad de población emigrante que volcó sus expectativas en los países europeos, sino también - y mucho más - al considerar a los recién llegados únicamente como proveedores de mano de obra y no como personas en su integridad, con derechos y deberes, con un bagaje cultural propio y con unas expectativas de vida que no se limitan al ámbito económico.

Actualmente, los dirigentes de los países de destino han dejado de considerar a la inmigración como una solución y la presentan ante la opinión pública como un problema, especialmente a los inmigrantes en situación irregular, que se han convertido en el chivo expiatorio de los asuntos relacionados con la seguridad, el orden público y el desempleo. Los representantes de los gobiernos "denuncian una 'invasión silenciosa' y aplican políticas de control, de disuasión y de represión en contra de los sin papeles, los nuevos parias de la humanidad que pueden desafiar el orden estatal" (Le Monde Diplomatique, 2010, p. 07).

La Unión Europea, con el objetivo de frenar la entrada de inmigrantes, ha desarrollado políticas migratorias que deben ser implementadas a través de las Leyes de Extranjería de cada país, que establecen quiénes, cómo y por cuánto tiempo pueden residir legalmente en territorio europeo; se ha incrementado presupuesto y esfuerzos en la implementación de instituciones de control de frontera (FRONTEX, Sive, Plan África, Proyecto ERA), se ha impulsado la creación de Centros de Internamiento de Extranjeros (CIEs) para retener a inmigrantes en situación irregular, y se han establecido procedimientos de expulsión de la población que no cuenta con permiso de residencia.

En medio de este entramado social, político, legal y administrativo, "los inmigrantes en el limbo jurídico", nominación que he adjudicado a los sujetos de estudio del presente trabajo, surgen como una paradoja dentro del sistema de control migratorio europeo. Las personas en el "limbo jurídico" son las y los inmigrantes en situación irregular que son detenidos en los Centros de Internamiento de 
Extranjeros (CIEs) para tramitar su expulsión, pero que por motivos legales o administrativos ésta no puede ser ejecutada, por lo que permanecen en territorio español con la orden de expulsión que, de acuerdo a la Ley de Extranjería, impide y anula cualquier trámite para su regularización. De este modo, viven en un estado de excepción: no son ni expulsables ni regularizables.

A través del estudio etnográfico de los inmigrantes que se encuentran en "limbo jurídico" se pretende articular el alcance de las políticas migratorias en la construcción de la persona migrante; exponer la forma en que las leyes interfieren y condicionan la vida de los migrantes constituyéndose en "marcos estructurantes de su accionar” (Herrera, 2008); y reflexionar sobre cómo la restricción de los derechos ciudadanos deviene en un proceso de despersonalización social y jurídico de los inmigrantes en situación irregular.

\section{Políticas migratorias, violación de derechos humanos y legislaciones excluyentes}

La integración de la Unión Europea (UE) ha modificado el mapa geopolítico mundial, estableciendo un nuevo orden tanto en las relaciones internas entre los estados miembros como en las relaciones con el resto de países. De acuerdo al Tratado de la Unión Europea, firmado en 1992, el objetivo de la UE es: “constituir un espacio de libertad, seguridad y justicia sin fronteras interiores".

En materia de migraciones, en el año 1999, los representantes de los gobiernos de los países miembros acuerdan la creación de una legislación común para la regulación de la inmigración. A partir de esta fecha, el Parlamento Europeo ha formulado Directivas concernientes a: Reunificación familiar (2003), Residencia de larga duración (2003), Residencia de trabajo (2003), Estancia por estudios e investigación (2003), Directiva del Retorno (2008). De acuerdo al Informe de la Comisión Europea (2004), estas Directivas están basadas en las necesidades económicas y en la capacidad de la UE para asimilar nuevos inmigrantes, estableciéndose, de esta manera, una clara diferencia de derechos, jerarquía y estatus entre la población comunitaria y extracomunitaria.

Esta dicotomía en la categorización de la población entre comunitarios y no comunitarios "es el resultado histórico de la imposición de determinada forma de visión y división que promueve un tipo de políticas, que mientras restringen y problematizan ciertos movimientos de población, facilitan y normalizan otros" (Gil Araujo, 2008, p. 381). De hecho, el término inmigración engendra en sí mismo una clasificación que alude específicamente a la población extranjera con derechos restringidos, mientras que los extranjeros procedentes de países "desarrollados" o en condiciones económicas privilegiadas son denominados por la opinión pública como extranjeros, sin más, estableciéndose un evidente tratamiento diferencial, "la noción de inmigrante se revela entonces como útil para operar una discriminación semántica” (Delgado, 2002, p. 18).

Los Estados a través de las leyes, del aparato administrativo y del discurso político que problematiza a la inmigración institucionalizan esta clasificación, naturalizándola (Bourdieu, 2007 [1997]) y de este modo posibilitan la vulneración de los derechos humanos de los inmigrantes, especialmente de quienes se encuentran en situación irregular. Cabe señalar que las Constituciones de los países europeos han otorgado el predominio de los derechos fundamentales sobre los derechos humanos 
304 | AdRIANA JARrín Morán

(Ferrajoli, 2002 [1999]; De Lucas, 1994). Los derechos fundamentales son "los derechos humanos concretados espacial y temporalmente en un Estado"3, por lo tanto, están garantizados únicamente para quienes el Estado reconoce legítimamente dentro de la jurisdicción de su territorio, es decir, a los ciudadanos. "Los 'derechos humanos', apuntaba Burke, son una abstracción, y los seres humanos difícilmente puedan esperar que esos 'derechos' los protejan, a menos que la abstracción se concrete en los derechos efectivos de un inglés o de un francés" (Bauman, 2009 [2003], p. 165).

Refiriéndose a los inmigrantes en el "limbo jurídico" una de las juristas especializadas en extranjería entrevistada durante el trabajo de investigación manifestó que los derechos humanos no constituyen un elemento argumental para la defensa de los inmigrantes que están imputados en un proceso de expulsión: "Cuando invocas a los derechos humanos su Señoría directamente piensa que no tienes nada mejor que decir (...), la vulneración de los derechos humanos es una cosa como muy genérica" (Entrevista Arlet Pallés, 22/05/2010).

\section{El "limbo jurídico"}

El "limbo jurídico" está provocado por los vacíos legales y la dualidad interpretativa, tanto de la Ley de Extranjería Española como de La Directiva Europea sobre las normas y procedimientos en los Estados miembros para el retorno de los nacionales de terceros países en situación irregular (Directiva del Retorno), aprobada en 2008 por el Parlamento Europeo.

El apartado 4 del Art. 15 de la Directiva, adoptado en la Ley española en el Art.62.3, señala que "las personas que no han podido ser expulsadas por motivos jurídicos o por otras con- sideraciones deberán ser puestas en libertad". Sin embargo, no se especifica el estatus legal de la persona una vez liberada. Por su parte, la Ley en el Art.58 sostiene que: "La expulsión conllevará, en todo caso, la extinción de cualquier autorización para permanecer legalmente en España, así como el archivo de cualquier procedimiento que tuviera por objeto la autorización para residir o trabajar en España del extranjero expulsado”. La articulación de ambas disposiciones genera el vacío legal que da a lugar al "limbo jurídico" 45. Los inmigrantes retenidos en los CIEs y que no han podido ser expulsados son puestos en libertad, sin embargo, la orden de expulsión continúa vigente, quedando exentos de iniciar cualquier procedimiento de regularización.

La Directiva del Retorno, concebida por la UE como el instrumento para viabilizar la lucha contra la "inmigración ilegal", establece una normativa común a los países miembros para la prohibición de la circulación y la aplicación de medidas para el retorno (expulsión) de personas en situación irregular. Para la implementación y funcionamiento de esta Directiva se ha puesto en marcha una plataforma de control de fronteras en el que participan, de manera coordinada, el Sistema de Información Schengen, la Agencia Europea para la Gestión de la Cooperación Operativa en las Fronteras Exteriores FRONTEX 6 , la EUROPOL - que tiene como objetivo la lucha contra formas graves de delincuencia y terrorismo internacional -, y la Escuela Europea de Policía para la Cooperación Transfronteriza CEPOL.

Las ONGs y las asociaciones de inmigrantes la han denominado como la "Directiva de la Vergüenza”, debido a que bajo el amparo de ésta, y mediante las Leyes de Extranjería de cada país, se instrumentalizan las normativas de control y exclusión de la población migrada. Para España, la incorporación de esta Directiva en la Reforma de la Ley de Extranjería en 2009 
supuso, además del refuerzo de las medidas de control de frontera, el incremento del tiempo de internamiento de inmigrantes en los CIEs de 40 a 60 días, reformas restrictivas respecto a la reagrupación familiar, y el endurecimiento de las sanciones a quienes acojan en sus hogares o empleen a personas en situación irregular con multas que oscilan entre los 500 y 10.000 euros.

La Ley de Extranjería de España establece el estatus jurídico de los extranjeros comunitarios y no comunitarios radicados en el país. Para el caso de los nacionales de países miembros de la Unión Europea, la Ley adjudica igualdad de derechos que los ciudadanos españoles. En relación con las personas procedentes de países extracomunitarios desarrolla una normativa que reconoce cinco condiciones para la residencia y estancia legal en el país: 1) permiso de trabajo, 2) arraigo social, 3) estancia por estudios y actividades de investigación, 4) reagrupación familiar, 5) asilo y refugio.

A excepción del grupo (3) el permiso de residencia en España está supeditado a la participación legal en el mercado laboral, por este motivo, las asociaciones de inmigrantes y ONGs afirman que la Ley de Extranjería considera a los inmigrantes por su mano de obra y no en tanto personas de derecho puesto que aquellas que no cuentan con un contrato de trabajo están restringidas de residir y circular legalmente por el país. "La lógica del guest worker (trabajador invitado) ha obviado que los/las migrantes no existen sólo en función de su dimensión o contribución económico-laboral en el país de acogida" (Gil Araujo, 2008, p. 120).

En lo que concierne a los inmigrantes en situación irregular, aproximadamente un millón de personas (D’Ancona; Valles, 2009), participan cotidianamente en el entramado productivo de la sociedad a través del mercado informal y del trabajo ilegal; sin derechos laborales que los amparen, están sujetos a la explotación y la inestabilidad laboral. Los inmigrantes que se encuentran en "limbo jurídico", debido a su condición de irregularizables, perpetúan esta situación de alegalidad pasando a formar parte de una bolsa de trabajo ilegal que se retroalimenta continuamente a la sombra del propio Estado. El trabajo ilegal está sometido a las fluctuaciones del mercado y marcado por una exigua compensación salarial, que tiene como consecuencia la paulatina reducción del coste de la mano de obra en el sistema productivo (De Lucas, 1997).

En este sentido, las Directivas Europeas y las Leyes de Extranjería ponen de manifiesto lo que Foucault denominó como la inscripción jurídica que consiste en la utilización del derecho como instrumento del poder que "transmite y hace funcionar relaciones que no son de soberanía sino de dominación" (2005 [1976], p. 30). El aparato legislativo concentra y objetiva "el capital simbólico" de los Estados en el que está inscrito el sistema de categorización y jerarquización social (incluidos - excluidos) que es instituido y aplicado a través de la acción de las administraciones públicas y los sistemas de control social (Bourdieu, 2007 [1997], p. 97).

En España, las instituciones encargadas de gestionar los procedimientos de regularización de la población migrada son el Gobierno Civil, por medio de sus Subdelegaciones, y las Comisarías de Policía. Los funcionarios de estas instituciones administrativas y de control social son quienes, sobre la base de la Ley, deciden respecto a los inmigrantes que son susceptibles de obtener el permiso de residencia o que deben ser expulsados del territorio nacional. En este sentido, De Lucas (1994, p. 196) afirma:

La diferencia más importante en cuanto a los derechos, lo que justifica que hablemos de exclusión, es precisamente que para ese sector de la población sus derechos son un problema de 
administración y policía, precisamente porque son ciudadanos de segunda: a ellos no les alcanza el grado de plena garantía, porque constituyen en sí un sector de la población que - como lo revelan no sólo su estatuto jurídico, sino el lenguaje mismo - todavía aparece más próximo a la condición de súbdito que a la de ciudadano.
La ejecución de los procedimientos de expulsión de los inmigrantes en situación irregular sigue un circuito discontinuo en el que participan instituciones administrativas y policiales que "actúan de forma desarticulada y sin criterios comunes de aplicación" (Entrevista Pallés, 22/10/2010 ${ }^{8}$. Ver el siguiente diagrama.

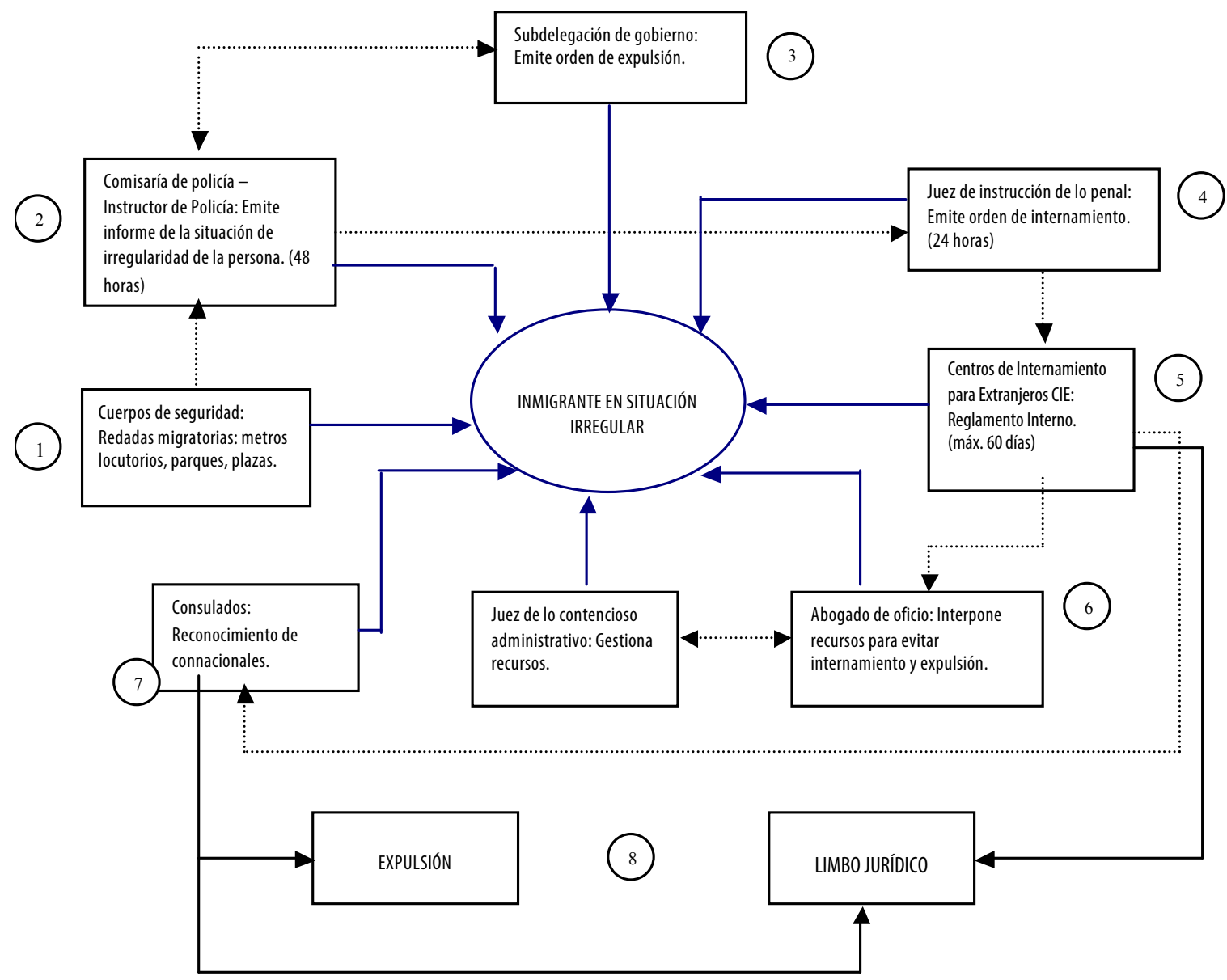

Figura 1. Procedimiento de expulsión de inmigrantes en situación irregular.

Fuente: Elaboración propia.

La policía es la encargada de llevar adelante las redadas migratorias, detener a las personas en situación irregular y llevarlas hasta Comisaría. El Instructor de Policía emite un informe al Juez de Instrucción (figura del sistema penal), que es quien dispone sobre la pertinencia del internamiento 9 . A la persona se le asigna un abogado de oficio para que presente las pruebas y recursos para evitar el internamiento en un plazo de 24 horas. Si el migrante cuenta con los requisitos necesarios para gestionar su regularización presentará un recurso ante el Juez de 
LA CONSTRUCCIÓN DE LA PERSONA INMIGRANTE EN EL LIMBO JURÍDICO 307

lo Contencioso Administrativo (figura del sistema civil) para archivar la orden de expulsión. En el Centro de Internamiento de Extranjeros la persona está sujeta al Reglamento Interno del CIE, cuyos criterios de aplicación recaen en la discrecionalidad del Director de cada Centro (Pérez-Sales, 2009).

Para ejecutar la expulsión los Consulados deben reconocer a la persona como connacional. Según el modelo de los Acuerdos de Readmisión establecido por la Unión Europea: "Cada país signatario debe readmitir en su territorio, sin ninguna formalidad previa, a toda persona que posea su nacionalidad y se encuentre en situación ilegal en otro país o haya cruzado sus fronteras ilegalmente" (C274UE, 1996). En los casos en los que se ha concluido la gestión de la orden de expulsión, la persona es acompañada por la Policía de Migración para abordar el medio de transporte (terrestre, marítimo o aéreo) para ser expulsada del país. Las personas que no son expulsadas debido a que han existido irregularidades en el procedimiento de expulsión son liberadas del CIE quedando en "limbo jurídico".

La complejidad y la fragmentación del procedimiento posibilita las irregularidades, arbitrariedad y vacíos en la aplicación de la normativa, sin que exista una responsabilidad institucional sobre los efectos de este entramado legal y administrativo. Las piezas de este rompecabezas únicamente se articulan en la persona migrante, que es la receptora de cada una de las decisiones tomadas en cada instancia del procedimiento y que condicionan y determinan sus circunstancias de vida.

El caso de las personas en el "limbo jurídico" pone en evidencia la incongruencia de la Ley, el complejo y disfuncional entramado del procedimiento legal y administrativo para gestionar la expulsión, y la desarticulación de las instituciones que participan de este proceso, que en lugar de garantizar los derechos de los y las migrantes crean y perpetúan condiciones de marginalidad.

\section{Centros de Internamiento de extranjeros: ruptura de la regularidad de la irregularidad}

Los Centros de Internamiento de Extranjeros (CIEs) en España se crean oficialmente el 1 de julio de 1985 por una Orden Ministerial para ejecutar la normativa de la primera Ley Orgánica de Extranjería sobre los Derechos y Libertades de los Extranjeros, que en el Art.26.2 señala: Acordar judicialmente, con carácter preventivo o cautelar, el ingreso en centros que no tengan carácter penitenciario de extranjeros incursos en determinadas causas de expulsión mientras se sustancia el expediente.

Los inmigrantes son detenidos en los CIEs debido a que han cometido una falta administrativa, pero no un delito. En este sentido, el Observatorio de Derechos Humanos de la Universidad de Barcelona (2008) ha calificado esta medida como inconstitucional porque "se detienen personas por lo que son y no por lo que han hecho".

La Ley de Extranjería, en el Art.60, establece que los CIEs "no tendrán carácter penitenciario y estarán dotados de servicios sociales, jurídicos, culturales y sanitarios”. Sin embargo, en la práctica operan como cárceles, tanto por la infraestructura de sus dependencias como por su funcionamiento, o aún en peores condiciones debido a la escueta normativa para su regulación interna (SOS Racismo, 2009). El Fiscal General del Estado, Cándido Conde Pumpido, en la memoria Anual del año 2005 ya señaló respecto a los CIEs que "cada vez se parece más a un centro penitenciario pero sin 
contar con las infraestructuras y personal cualificado de los mismos" (Memoria Ministerio Fiscal 2005, cap.III, p. 127).

Los CIEs, desde su creación, están a cargo del Ministerio de Interior, existiendo CIEs en nueve ciudades españolas: Madrid, Barcelona, Valencia, Málaga, Fuerteventura, Gran Canaria, Murcia, Algeciras y Tenerife, con una capacidad total para internar a 2.718 personas.

El trabajo de campo para la investigación en torno a los Centros de Internamiento de Extranjeros se desarrolló en el CIE de la Zona Franca de Barcelona. Durante cuatro meses se realizaron visitas semanales al Centro para entrevistar a los internos y a los familiares. Los testimonios de los internos en el CIE se recogieron en calidad de visitante debido a la prohibición de entrada a las instalaciones internas del CIE, y el contacto con los familiares se estableció en la sala de espera del Centro y en los autobuses públicos durante los viajes hacia el CIE.

A partir de la información recabada y del trabajo de campo se elaboró una tipología orientativa de los inmigrantes internos en los CIEs que en base a la condición migratoria las he clasificado en cuatro grandes grupos:

1) Interceptados en la travesía: a este grupo pertenecen las personas procedentes especialmente del África Sudsahariana que viajan en embarcaciones hasta las costas españolas y son interceptados antes o al llegar a territorio espańol;

2) Personas que han cumplido pena de cárcel: de acuerdo a la Ley los inmigrantes que han cometido delitos menores pueden elegir entre cumplir la sentencia en centros penitenciarios españoles o ser expulsados a sus países de origen, sin embargo, existen casos en los que aún habiendo cumplido la sentencia son trasladados directamente de la cárcel al CIE para su expulsión;

3) Personas con permisos de residencia caducados: inmigrantes que, habiéndose encontrado en si- tuación regular, al no contar con un contrato laboral para renovar sus permisos de trabajo pierden el derecho de residencia;

4) Migrantes en situación irregular establecidos en España: son personas de diversa procedencia geográfica: América Latina, África, Asia y Europa del Este que han ingresado al país de forma irregular o mediante una visa de turismo y que han permanecido residiendo y trabajando sin los permisos necesarios. Este último (4) fue el grupo sobre el cual se desarrolló el trabajo de investigación.

Los datos publicados en el informe de CEAR exponen que el $25 \%$ de las personas retenidas en los CIEs corresponde a la categoría (1) interceptados en la travesía, del 75\% restante el 40,2\% ha residido de 4 a 10 años en España, el 15,9\% de 1 a 3 años, el 9,4\% menos de un ańo, el 5,6\% de 10 a 19 ańos, y el 2,8\% 20 años o más (Pérez-Sales, 2009, p. $80)$. En este sentido, más del $60 \%$ de las y los inmigrantes detenidos han residido en España por un periodo superior a un ańo, tiempo en el que, pese a su condición de irregularidad, han establecido redes familiares, sociales y laborales, que se verán interrumpidas con la expulsión o amenazadas en el caso de las personas en el "limbo jurídico".

En base a la observación directa, a los testimonios recogidos, a las historias de vida, a las entrevistas realizadas y a los informes revisados sobre la situación de los internos en los Centros de Internamiento de Extranjeros en España, a continuación se realizará una descripción de los aspectos más relevantes acerca de las condiciones de los CIEs enfocada en tres puntos: a) Irregularidades en la aplicación del Reglamento, b) Condiciones de las dependencias internas y externas del CIE, c) Condiciones personales de los internos. 


\section{a) Irregularidades en la aplicación del Reglamento.}

El 22 de febrero de 1999, catorce años después de la creación de los CIEs, se publica la primera orden ministerial que regula su régimen interno; hasta entonces, únicamente existían "criterios orientativos" señalados por la Comisaría General de Extranjería (Guerrero, 2007). El actual Reglamento de funcionamiento de los CIEs regula los derechos y obligaciones de los internos, sin embargo, no hace alusión a los procedimientos y protocolos de comportamiento de los funcionarios, hecho que deja un amplio margen de discreción en el momento de aplicar las normativas de control. El Reglamento tampoco establece las normas de convivencia dentro del CIE en cuanto a horarios, utilización de espacios, aplicación de castigos, regulación de visitas, etc., normas que son pautadas por el Director de cada Centro.

Durante el trabajo de campo, a través de los testimonios de los internos y de la observación directa, se constató abuso, arbitrariedad y maltrato de los funcionarios hacia los internos, expresada a través de la utilización de fuerza física, el uso de celdas de aislamiento e incluso de fármacos como mecanismos de control. En una visita de seguimiento realizada a un interno una semana después del primer contacto encontramos que éste había sido golpeado, evidenciando severas contusiones en la cara y llevando la mano derecha escayolada, además de encontrarse bajo el efecto de fármacos que dificultaban la conversación. De acuerdo a su testimonio, estaba recibiendo medicación debido a fuertes cefaleas, afirmó que desde que ingería las medicinas sentía mareos, sensación de estar "volado" y sueño permanente: "Lo único que pido es que no me vuelvan a tocar" (Carlos Rocha, 21/05/2010).
El psiquiatra Joseba Achotegui, en una conferencia dictada en la ciudad de Barcelona ${ }^{10}$, señaló: "La seguridad física es la segunda necesidad fisiológica y psicológica básica de la persona, no hay seguridad en este sentido para los inmigrantes, la policía aprovecha esta situación de indefensión para expulsarlos".

En los testimonios de vida recogidos, todas las personas entrevistadas aseguraron haber presenciado más de un incidente de aplicación de violencia física durante su estancia en el CIE. Los informes sobre los CIEs realizados por CEAR, SOS Racisme y Ferrocarril Clandestino - entidades que en 2009 , por disposición ministerial y exclusivamente para la elaboración de los informes, tuvieron acceso a las dependencias internas de los Centros - corroboraron la existencia de celdas de aislamiento, recogieron testimonios de maltrato físico e incluso tortura (Pérez-Sales, 2009, p. 134). El Reglamento, por su parte, establece: "se velará por el respeto a su vida, integridad física y salud, sin que puedan en ningún caso ser sometidos a tratos degradantes o a malos tratos de palabra o de obra y a que sea preservada su dignidad y su intimidad".

Para el caso de las personas que son puestas en libertad, en "limbo jurídico", el Reglamento estipula la obligatoriedad de entregar al interno un certificado en el que conste el tiempo que ha permanecido retenido, que en ningún caso podrá superar los 60 días establecidos en la Ley. Sin embargo, existen irregularidades en la entrega de este documento, de manera que la persona liberada queda expuesta a ser nuevamente detenida y llevada a un CIE. En uno de los testimonios referidos en el Informe de CEAR (Pérez-Sales, 2009, p. 140), un interno manifiesta: "No te dan ninguna documentación, ningún papel que conste que tú estabas dentro del CIE, eso es lo peor porque tú sales y en la esquina mismo te agarran y te vuelven a meter". 
3 IO | Adriana Jarrín MorÁn

\section{b) Condiciones de las dependencias y funcionamiento del CIE:}

De acuerdo a la información recabada y corroborada por los testimonios de los entrevistados, las dependencias internas de los CIEs corresponden a las de un centro penitenciario. En el caso del CIE de Aluche en Madrid, por ejemplo, funciona en las antiguas dependencias de la cárcel de Carabanchel; en Barcelona, el CIE funcionaba en los calabozos de la Comisaría de Policía la Verneda hasta que en 2006 se construyó el CIE de la Zona Franca. En la entrevista realizada como parte de la investigación, una trabajadora de CEAR que ingresó a las dependencias internas del CIE de Zapadores, en Valencia, describe las habitaciones de la siguiente manera:

Cuando digo celdas hablo de barrotes de hierro, de llaves que las cierran y las abren, no existen mecanismos automáticos de apertura [...] Las camas se organizan en literas, no tienen baño, únicamente hay una pila que la tienen que utilizar para hacer sus necesidades dado que en la noche no hay posibilidad de ir al servicio (27/05/2010).

Los espacios de uso común son reducidos, existe restricción en los horarios de acceso y están permanentemente controlados por cámaras de vigilancia; la mayor parte del tiempo durante el día transcurren en los pasillos y el comedor. El espacio y tiempo del patio lo aprovechan para lavar ropa, utilizando las vallas como tendederos, debido a que no existen lugares destinados para lavandería.

Las actividades que pueden realizar son escasas, más allá de ver la televisión; no existen materiales de ocio como juegos de mesa, libros, revistas, etc. Sin embargo, una actividad importante permitida en los CIEs es la celebración del culto religioso, se concede la entrada de sacerdotes y pastores para la celebración de la Misa y el Culto Cristiano, respectivamente, se establecen horarios diferenciados de comida durante el tiempo de la celebración del Ramadán para la población musulmana, etc. Este espacio es un elemento generador de lazos de acompañamiento, solidaridad y reciprocidad entre los internos.

Para la asistencia sanitaria de los internos existe un espacio dispuesto como enfermería, sin embargo no hay regularidad en la presencia de personal médico; los tratamientos de los internos que padecen enfermedades crónicas, como síndrome de inmunodeficiencia humana VIH, diabetes, hepatitis, etc., son interrumpidos puesto que no se permite el ingreso de fármacos al Centro y tampoco se les dota de la medicación requerida.

En lo que concierne a las dependencias externas, se encuentran las salas de visita, dividas en cabinas separadas por mamparas de vidrio que impiden el contacto físico de los internos con sus visitantes, la comunicación se realiza por interfono.

\section{c) Condiciones personales de los internos.}

Los inmigrantes internos en los CIEs, al estar sometidos a un régimen penitenciario, sufren un deterioro físico y psíquico importante. De acuerdo al Reglamento, las revisiones médicas son obligatorias tanto en el momento de la entrada como en el de salida del CIE; sin embargo, el examen médico se traduce en una inspección exhaustiva para confirmar que la 
persona no porta ningún tipo de sustancias ilícitas. Este procedimiento carece de justificación puesto que los internos son detenidos por encontrarse en situación administrativa irregular y no por haber cometido delito alguno. Oliver du Arte, en su testimonio, explica este evento de la siguiente manera: "Me llevaron a la parte interior del centro y me hicieron el procedimiento de rutina, revisión corporal, desnudo y a profundidad, y cuando digo en profundidad digo en profundidad" (02/03/2010).

En los internos que no reciben visitas, ya sea porque el CIE se encuentra en una ciudad diferente a la de su residencia, porque no tienen una red social o porque sus familiares también se encuentran en situación irregular, el deterioro es más visible. No cuentan con productos para el aseo y cuidado personal, permanecen durante días con la misma ropa, desde el momento de la detención hasta la expulsión o liberación. Raba, en su testimonio, expuso:

Me llevaron ante el juez, imagínate una persona que no se ducha durante cuatro días delante del juez, con la barba crecida, la ropa sucia. ¿Cómo iba a mirar así al juez? Te presentas, yo soy así, he estado en tal país, estuve estudiando, estuve trabajando y quiero integrarme a la sociedad, pero así como estás el juez no te cree.

La ambigüedad de estar detenidos sin haber cometido un delito provoca un cuestionamiento identitario, frases como "yo no he cometido un delito", "yo no soy un criminal”, "yo no le he hecho mal a nadie", fueron frecuentes en las conversaciones con los internos. El apartado psicosocial del informe de CEAR (Pérez-Sales, 2009, p. 177) señala que un 33\% de los detenidos manifestaron que "este encierro les está destruyendo como persona”. Otras con- secuencias psicológicas recogidas a través de una encuesta realizada para la elaboración del informe son: cuestionamiento de la visión del ser humano, sentimientos de odio y deseos de venganza debido a la afectación del sistema de creencias, sentimientos de rabia contra sí mismos o hacia los demás y sentimientos de odio (Pérez-Sales, 2009, p. 178)

Debido a que no están establecidas las fechas ni los horarios para la concreción de la expulsión, éstas se realizan incluso en horas de la madrugada, por este motivo los internos permanecen en un estado permanente de vigilia. Esta situación ha sido descrita por Richard en su testimonio:

Es una cosa horrorosa, ¿sabe lo que hace falta ahí? No uno, sino dos o tres psicólogos que te orienten, porque, si no, estamos ahí las personas dando vuelta al cerebro pensando, pensando, pensando, en los papeles, el contrato. No podía dormir, escuchaba las rejas que sonaban y decía me van a llamar, ya me llevan. No hay justicia. $(19 / 06 / 2010)$

Desde 2008 sólo en el CIE de la Zona Franca de Barcelona, centro en el que se desarrolló el trabajo de campo, se ha registrado la muerte de tres internos: de Ecuador (2008) y de Marruecos (2010) por suicidio, y de Guinea-Conakry (2012) por falta de asistencia médica e intérpretes. Estos casos revelan la vulneración de derechos, el estrés psíquico y la carencia de condiciones básicas que existen en estos Centros.

Desde la entrada en vigencia de la Reforma de la Ley de Extranjería en 2009 diversas organizaciones de la sociedad civil han creado una plataforma para denunciar las condiciones de vulnerabilidad a las que están expuestos los in- 
migrantes retenidos en los CIEs, así como para informar a la ciudadanía sobre la existencia de estos Centros.

\section{La construcción de la persona inmigrante en el "limbo jurídico"}

"Los ilegales", "los sin papeles", son los términos con los que habitualmente se hace alusión a la población en situación irregular. Esta denominación, que etimológicamente aparecería como descriptiva de una condición, simbólicamente no lo es, pues tiene un impacto en la concepción que se tiene comúnmente de las personas en situación irregular, y un impacto aún mayor en la percepción que el migrante tiene de sí mismo como detentor de la condición de "ilegal", en la medida que apela al "ser" y no al "estar" o al estatus legal por el que atraviesa la persona inmigrante.

Marcel Mauss, en el estudio de la construcción histórica de la persona respecto a las sociedades occidentales sostiene que "la persona es algo más que el resultado de una organización, es algo más que el nombre o el derecho de un personaje o de una máscara ritual, es fundamentalmente un hecho de derecho" (1979, p. 323). En esta medida, la persona no es únicamente en su humanidad - dotada de atributos culturales y sociales - sino que es el resultado del compendio de normas jurídicas que le atribuyen unos derechos y deberes (Kelsen, 1975), estableciéndose así una aproximación del concepto de persona al de ciudadano. Siguiendo esta dualidad persona-ciudadano podríamos decir que bajo el estigma de la "ilegalidad" se anula la dimensión como personas de los inmigrantes en situación irregular por el solo hecho de encontrarse al margen de la ley. La obtención del permiso de residencia se figura entonces como una suerte de ritual de paso para ser reconocidos en tanto personas (ciudadanos). Dal Lago, quien ha desarrollado ampliamente el concepto de no-persona en el ámbito migratorio, manifiesta:

Mi tesis es que los extranjeros jurídica y socialmente ilegítimos (emigrantes regulares, irregulares, clandestinos, nómadas, prófugos) son las categorías más susceptibles de ser tratadas como no personas, esto es, son aquellos seres humanos que intuitivamente son personas como nosotros (seres humanos vivos dotados de una persona social y cultural), pero a los que les son revocadas - de hecho o de derecho, implícita o explícitamente, en las transacciones ordinarias o en el lenguaje público - la calificación de personas y sus atribuciones relativas (2002 [1999], p. 129).

Para quienes se encuentran en el "limbo jurídico" su situación de irregularidad ha sido develada. Sustraídos de la masa difusa de "los nadie", representada por los "ilegales", han sido identificados y tocados por la Ley, y sin embargo, este roce con la Ley en lugar de reconocerlos como personas refuerza más que nunca su condición de marginales. La paradoja de la Ley determina que la irregularidad se constituya en un hecho estructural, permanente y crónico ${ }^{11}$, sentenciándoles a vivir en un permanente estado de excepción. Agamben sostiene que "lo que caracteriza a la excepción es que el objeto de exclusión no está simplemente desligado de la ley; al contrario, la ley se mantiene en relación con él bajo la forma de la suspensión" (2000 [1996], p. 87).

Este estado de excepción se hace extensivo a sus espacios privados, que se ven condicionados por la incertidumbre que marca el ritmo de su tiempo, atraviesa sus expectativas de futuro 
y determina su condición: ni dentro ni fuera, sino en el límite. De este modo, la orden de expulsión es una "frontera" que cargan consigo, equiparando su condición a la de un rehén: "el rehén está pendiente de un vencimiento incalculable. No le acecha su destino, ni su propia muerte, sino un azar anónimo que sólo puede presentársele como una arbitrariedad absoluta" (Baudrillard, 2000 [1984], p. 35). En este sentido, la permanencia en territorio espańol sin el permiso de residencia implica la restricción de su condición en tanto persona-ciudadano, por otra parte, la expulsión significaría una muerte simbólica en el país de destino y la frustración de su proyecto migratorio.

El "limbo jurídico" cristaliza el papel del Estado como productor de "ilegalidad" a través de la ambigüedad en la elaboración y aplicación de la Ley y de los procedimientos administrativos de control de la inmigración. La exclusión que encarna la persona inmigrante en el "limbo jurídico" se aproxima a la del homo sacer, figura del antiguo derecho romano recuperada por Agamben (2000 [1996]), que alude a los seres humanos eximidos de todo derecho y "arrojados más allá de los límites de la ley”. Paradójicamente, la existencia de "los sin papeles" justifica la creación de medidas de control social extraordinarias: establecimiento de sistemas de control de frontera, aprobación de normativas y leyes migratorias, redadas, y la creación de instituciones como los CIEs.

La detención y el internamiento en los CIEs es un hecho constitutivo de la persona en el "limbo jurídico". La experiencia del encierro, por la que necesariamente han atravesado quienes se encuentran en esta condición, determina una forma de comportamiento durante el internamiento y después de la liberación. El sistema carcelario en el que se inscriben los CIEs imprime en la subjetividad de la persona la falta de control sobre la propia vida (House,
1998, p. 145) y cristaliza el alcance del poder del Estado ejecutando sobre el individuo las leyes y los mecanismos de control.

Los diversos rituales de iniciación y de sumisión en la cárcel o en otras instituciones totales (como los manicomios) prevén la inserción del detenido o del interno en procedimientos disciplinarios que destruyen el respeto de la persona: inspecciones corporales humillantes (a las que se agregan las cuestiones culturales). Alteración de los tiempos de vigilia y de sueño, camisa de fuerza, reducción de la distancia física entre él y los otros, eliminación de la intimidad, obediencia ciega a reglamentos de sentido oscuro o carentes de sentido (Agamben, 2000 [1996], p. 129).

Socialmente, en la percepción de la opinión pública, los CIEs están concebidos como "cárceles para inmigrantes". Esta concepción se basa en los discursos de los gobiernos, que problematizan la inmigración vinculándola con patologías sociales como la delincuencia, la criminalidad, el terrorismo, el narcotráfico, etc. (De Lucas, 1994). Estas narrativas se materializan en acciones cotidianas concretas, como las redadas migratorias en espacios públicos llevadas a cabo por los cuerpos policiales, por las imágenes difundidas en los medios de comunicación en las que se subrayan las distinciones étnicas de los inmigrantes, por las estadísticas que simplifican y muestran la inmigración como uno de los problemas prioritarios de la ciudadanía ${ }^{12}$. "Si el Estado está en condiciones de ejercer una violencia simbólica es porque se encarna a la vez en la objetividad bajo forma de estructuras y de mecanismos específicos y en la 'subjetividad' o, si se prefiere, en los cerebros, bajo forma de estructuras mentales, de percepción y de pensamiento" (Bourdieu, 2007 [1997], p. 98). 
Las detenciones de los inmigrantes suelen llevarse a cabo mediante redadas realizadas en lugares comunes a sus rutinas: a la entrada del metro, en plazas y parques, en locutorios; y en cualquier momento: al salir a trabajar, al retornar a casa, a la salida de una cafetería, etc. De esta manera, los espacios cotidianos se convierten en los escenarios en los que operan los dispositivos de control y adquieren una nueva representación: pasan de ser lugares de circulación a enclaves de control. Una vez liberados del CIE, los inmigrantes en "limbo jurídico" vivencian una sensación constante de vigilancia y persecución, de magnificación del poder de los cuerpos de seguridad, de pérdida de dominio sobre la vida y de inseguridad. El encierro, en este sentido, ha sido interiorizado y sale a la superficie cada vez que se activa un recuerdo, un lugar, una situación que dispara la experiencia de la detención y del internamiento (Foucault, 2005 [1976]).

Un denominador común, expresado por las personas en "limbo jurídico" entrevistadas para la investigación fue que durante las dos o tres semanas posteriores a la liberación del CIE no salieron de sus casas por temor a encontrarse nuevamente con una redada migratoria; luego de este periodo modificaron sus rutas de tránsito y sus espacios de socialización. Richard, en su testimonio, expresó:

Me iba a trabajar, me cogieron en la entrada al metro de Can Vidalet, aquí al lado de mi casa. Ahora me da miedo salir y que me vuelvan a coger, no salgo de mi casa, no quiero ir al metro, yo no quiero que me encierren, tengo un trauma, yo no quiero volver ahí, eso es algo muy feo, yo nunca había estado detenido (19/06/2010)

Los inmigrantes en el "limbo jurídico" participan informalmente del entramado social, forman parte del paisaje cotidiano a través de la utilización de los espacios públicos e interactúan como pares con el resto de la ciudadanía siempre y cuando estas transacciones no comporten relaciones de poder. La condición de "ilegalidad" que el Estado le ha atribuido a la persona es la que deviene en un tratamiento desigual que se disemina en los espacios habituales de intercambio social, perpetuando las condiciones de marginalidad para acceder a bienes básicos como vivienda, salud y trabajo.

Las personas en el "limbo jurídico" están especialmente expuestas a condiciones de explotación, debido a que carecen de derechos laborales su valor es proporcional únicamente con su capacidad de producir. "La destrucción del otro/distinto como persona lleva consigo que el cuerpo ajeno sea considerado como una 'máquina de trabajo”' (Barcellona, 2000, p. 115). A la sombra de la Ley, los inmigrantes en el "limbo jurídico” encarnan una suerte de esclavitud moderna que es naturalizada como una consecuencia lógica de su condición de "ilegalidad" o de no persona - no ciudadano. La precariedad de su situación permea las subjetividades de la (no) persona condicionando sus expectativas de vida y forzándola a transitar por "una identidad diferente de la que él esperaría le fuera concedida" (Dal Lago, 2002 [1999], p. 140) ${ }^{13}$.

En conclusión, la construcción de la persona-ciudadano, que por exclusión engendra la categoría no persona - no ciudadano en la que se inscriben los inmigrantes en el "limbo jurídico, pone una vez más de relieve las distinciones de jerarquía que los Estados europeos, y en concreto España, imponen entre la población comunitaria y no comunitaria. Como afirma Ferrajoli, "la ciudadanía de nuestros ricos países constituye el último privilegio de status, el último factor de exclusión y discriminación, el último residuo premoderno de la desigualdad personal en contraposición a la proclamada 
universalidad e igualdad de los derechos fundamentales" (2002 [1999], p. 246).

Los inmigrantes no comunitarios en situación irregular al no ser reconocidos como ciudadanos permanecen carentes de determinados derechos básicos dentro de las fronteras de los países de destino, "el universal jurídico, que aparentemente se muestra capaz de acoger todas las diferencias y de instituir el individuo particular como titular de derechos, acaba en realidad neutralizándolas, transformándolas en diversidades reconductibles al esquema de la transacción de los intereses" (Barcellona, 2000, p. 119).

Existe, sin duda, una interdependencia entre las causas que motivan las migraciones fruto de la relación de dominio de unos países sobre otros y mientras éstas no se resuelvan como una responsabilidad global los movimientos migratorios no cesarán. Por su parte, los gobiernos de los países receptores continúan utilizando la inmigración como una cortina de humo ante los problemas de fondo que aquejan actualmente a la ciudadanía europea. La "lucha contra la inmigración” justifica la creación de medidas que, más allá de restringir la circulación de un sector de la población, refuerzan la construcción de una sociedad permanentemente vigilada que en su obsesión por la seguridad ha hipotecado desde hace tiempo su libertad (Baudrillard, 2000 [1984]).

\section{A construção da pessoa imigrante no limbo jurídico: nem deportados nem regularizados na Espanha}

resumo $\mathrm{O}$ objetivo deste estudo é refletir sobre a forma como tem sido afetada a vida de imigrantes em situação irregular que, devido a um paradoxo na Lei de Imigração da Espanha, não podem ser deportados nem regularizados. O trabalho utilizou como metodologia a investigação etnográfica que, através da análise concreta de imigrantes em "limbo jurídico", permitiu articular o alcance das políticas de migração na construçấo da pessoa imigrante, expor a forma em que as leis condicionam a vida do imigrante e dimensionar como a restrição dos direitos dos cidadáos torna-se um processo de despersonalização social e jurídica de imigrantes em situação irregular. Os eixos temáticos são: a) Políticas migratórias: legislaçôes excludentes; b) Centros de Internamento de Estrangeiros: ruptura da regularidade e da irregularidade; c) A construção da pessoa imigrante no limbo jurídico.

palavras-chave Políticas migratórias. "Limbo jurídico”. CIEs. Pessoa / Não-Pessoa. Exclusão.

\section{Notas}

1. Esta comunicación es fruto de la investigación realizada para la tesis final del Master en Investigación etnográfica, teoría antropológica y relaciones interculturales, cursado en la Universidad Autónoma de Barcelona, $2009-2010$.

2. adrianajarrin@gmail.com

3. Enciclopedia-jurídica-biz14.

4. En España, el principal motivo para que una persona sea puesta en libertad del CIE es el vencimiento del plazo de internamiento sin que se haya gestionado su expulsión debido a que: a) la Embajada o Consulado del país consultado no le ha reconocido como connacional, b) no se ha podido tramitar los documentos necesarios para la extradición, pasaporte o salvoconducto, c) el gobierno español no tiene convenio bilateral de readmisión de personas en situación irregular con el país de origen del extranjero.

5. Los migrantes en "limbo jurídico" permanecerán bajo esta condición de alegalidad hasta que prescriba la orden de expulsión que pesa en su contra que, según el Art.121 del Reglamento de la Ley de Extranjería, es proporcional al tiempo de prohibición de entrada al país que, por lo general, fluctúa entre tres a cinco años, y diez años para casos excepcionales. En la práctica legal, a este tiempo deberá añadirse dos años, correspondientes a la prescripción de la infracción grave 
que, según el Art.53 de la Ley, supone "encontrarse irregularmente en territorio español”. En definitiva, la persona ha de esperar un plazo de cinco a siete años para iniciar un trámite de regularización, tiempo en el que correrá el riesgo permanente de ser detenido/a de nuevo.

6. Creada en 2004 esta entidad promueve y coordina acciones conjuntas entre los estados miembros para: 1) la creación de patrullas de guardias de frontera, encargadas de interceptar las pateras en alta mar, por ejemplo, 2) formar personal especializado en control de fronteras externas, 3) organizar operaciones conjuntas de retorno, 4) investigar y dar seguimiento sobre la eficiencia del control de fronteras. http://www.frontex.europa.eu

7. De acuerdo al Art. 33 de la Ley, los estudiantes obtienen un permiso de "estancia" y no de residencia, por tanto sus derechos respecto a servicios sociales y sanitarios son limitados. Para obtener el permiso de estancia deben presentar un seguro médico privado y un depósito de dinero en una cuenta bancaria, proporcional al tiempo de duración de estudios, que garantice la cobertura de los gastos de estancia. El tiempo de vigencia del permiso está determinado por la duración de los estudios, este tiempo no es acumulable para acceder a otro tipo de derechos como permisos de residencia o nacionalidad.

8. Fragmento de una entrevista realizada a dos Secretarias de un Juzgado de Instrucción en Cataluña. "A nosotros nos llega la petición desde la Delegación de Policía, únicamente lo que hacemos es gestionar el internamiento, porque se supone que la delegación ya ha visto que éste es necesario. Luego el juez firma la resolución y ya es asunto de la policía devolverlo a su país. Nosotros sólo somos "esto" (se señala la punta del dedo meñique) dentro de todo el proceso de expulsión. Es más, es algo que incluso no sabemos por qué tiene que pasar por una resolución judicial cuando es un tema administrativo que a nosotros no nos compete". En este Juzgado emiten diariamente un promedio de tres órdenes de internamiento de inmigrantes en CIEs (más de mil al año).

9. Los migrantes detenidos y llevados a los CIEs generalmente cuentan con una orden de expulsión emitida previamente por la subdelegación de gobierno y que ha sido notificada al domicilio de la persona. La orden de expulsión comunica que tiene un plazo de 7 a 30 días para abandonar voluntariamente el país. La mayoría de las personas no cumple con esta orden por lo que al ser detenidos nuevamente se les imputa por haber incumplido una orden administrativa.
10. Conferencia dictada en el marco del encuentro sobre: Centros de Internamiento, Externalización de las Fronteras: vulneración de derechos en la U.E., organizada por la Associació catalana de profesionals de l'estrangeria ACPE, celebrado en la Casa de la Caritat-Pati Manning, Barcelona, 02 de julio de 2010.

11. Para el trabajo de investigación entre marzo y junio de 2010 se recogieron cinco historias de vida de personas que se encontraban en situación de "limbo jurídico". En septiembre de 2011 nuevamente se estableció contacto con los inmigrantes entrevistados que manifestaron continuar en igual condición de "alegalidad". En octubre de 2011 uno de ellos fue detenido y llevado nuevamente al CIE de Barcelona.

12. Los datos publicados por el CIS en septiembre de 2011 exponen que la inmigración es el problema prioritario para el $12 \%$ de la población.

13. Un elemento en común planteado por tres de las personas que brindaron sus testimonios de vida fue la imposibilidad de formar una familia debido a la incertidumbre económica, de habitabilidad y de permanencia en el país.

\section{Referências bibliográficas}

AGAMBEN, Giorgio. Política del Exilio. In: SILVEIRA GORSKI (Org.). Identidades Comunitarias y Democracia. Madrid: Trotta, 2000 [1996]. p. 81-93.

AGAR, Michael. Hacia un lenguaje etnográfico. In: REYNOSO, C. (Org.). El surgimiento de la antropología posmoderna. Madrid: Gedisa, 1992. p. 117-137. ACHOTEGUI, Joseba. El Síndrome del Inmigrante con estrés crónico y múltiple. In: Jornadas sobre "Centros de Internamiento, externalización de Fronteras: Vulneración de derechos en la U.E”. ABEDIE, ACPE, Barcelona 2 de julio de 2010.

ASOCIACIÓN PERMANENTE POR LOS DERECHOS HUMANOS DE ANDALUCÍA. Informe Centros de Internamiento y retención en España, Madrid: Área de Inmigración de la APDHA, 2008.

BARBERO, Iker. Hacia modelos alternativos de ciudadanía: Un análisis socio-jurídico del movimiento Sinpapeles. Tese de doutorado - Universidad del País Vasco, 2010.

BARCELLONA. El vaciamiento del sujeto y el regreso del racismo. In: SILVEIRA GORSKI (Org.). Identidades Comunitarias y Democracia. Madrid: Trotta, 2000. p. 113-126. 
BAUDRILLARD, Jean. Las estrategias fatales. Barcelona: Anagrama, 2000 [1984].

. Cultura y simulacro. La precesión de los simulacros. El efecto Beaubourg. A la sombra de las mayorias silenciosas. El fin de lo Social. Barcelona: Kairós, 1998 [1978].

BAUMAN, Zygmunt. Amor líquido. A cerca de la fragilidad de los vínculos humanos. Madrid: Fondo de Cultura Económica, 2009 [2003].

Vidas desperdiciadas. La modernidad y sus parias. Barcelona: Paidós, 2007 [2004].

BODEI, Remo. Los sin Patria. In: SILVEIRA GORSKI (Org.). Identidades Comunitarias y Democracia. Madrid: Trotta, 2002 [1999]. pp. 153-165.

BOURDIEU, Pierre. Espíritus de Estado: génesis y estructura. In: Razones Prácticas. Barcelona: Anagrama, pp. 91 -125, 2007 [1997].

CACCIARI, Máximo. La paradoja del extranjero. In: SILVEIRA GORSKI (Org.). Identidades Comunitarias y Democracia. Madrid: Trotta, 2002 [1999]. pp. $147-151$.

CASSARINO, Jean-Pierre. Theorising Return Migration: The Conceptual Approach to Return Migrants Revisited. International Journal on Multicultural Societies, v. 6, n. 2, pp. 253-279, 2004.

CASTLES, S., MILLER, M. The age of migration: International Population Movements in the Modern World. Londres: Macmillan, 2009 [1993].

D’ANCONA, M., VALLES, M. Informe Evolución del Racismo y la Xenofobia en España. Madrid: Ministerio de Trabajo e Inmigración y el Observatorio Español del Racismo y la Xenofobia, 2009.

DAL LAGO, Alessandro. Personas y no personas. In: SILVEIRA GORSKI (ed.). Identidades Comunitarias y Democracia. Madrid: Trotta, 2002 [1999]. pp. 127144.

DE LUCAS, Javier. El Desafío de las Fronteras. Madrid: Ensayo, 1994.

. La desaparición del extranjero y su sustitución por el inmigrante: Estrategias de legitimación en la Unión Europea Hoy. In: DELGADO, M (Org). Ciutat i inmigració. Barcelona: Centro de Cultura Contemporánea de Barcelona CCCB, 1997.

DELGADO, Manel. Diversitat i integració. Barcelona: Empuréis, 1998.

- ¿Quién puede ser inmigrante en la ciudad? In: VV.AA. Exclusión social y diversidad cultural. San Sebastián: Gakoa, 2002. pp. 9-24.

DIRECCIÓN GENERAL DE JUSTICIA Y ASUNTOS DE INTERIOR. Hacia una politica de inmigración común en la UE. Bruselas: B-1049, 2004.
FERRAJOLI. De los derechos del ciudadano a los derechos de la persona. In: SILVEIRA GORSKI (Org.). Identidades Comunitarias y Democracia. Madrid: Trotta, 2002 [1999]. pp. 235-250.

FERROCARRIL CLANDESTINO, MÉDICOS MUNDO, SOS RACISMO. Voces desde y contra los Centros de Internamiento de Extranjeros. Madrid, 2009. Disponível em: <http://www.vocescontraelmuro.tk/>. Acessado em 10 jan. 2012.

FOUCAULT, Michel. Vigilar y castigar: Nacimiento de la prisión. Buenos Aires: Siglo XXI, 2005 [1976].

. Genealogía del racismo. La Plata: Altamira, 1996 [1976].

GIL ARAUJO, S., AGRELA, B. Un mundo en movimiento. Contextualización de las migraciones internacionales en Europa y América Latina. Revista de Derecho Migratorio y Extranjería, v.18, 2008.

GIL ARAUJO, Sandra. Políticas de migración familiar en Europa. El gobierno de la inmigración a través de las familias. In: PEDREÑO, A et al. (Org.) Tránsitos Migratorios. Contextos transnacionales y proyectos familiares en las migraciones actuales. Universidad de Murcia, 2010. pp. 47-84.

GUERRERO, Andrés. Inmigrantes e indios: dos casos comparativos de administración de las poblaciones. Quito: Facultad Latinoamericana de Ciencias Sociales, 2007.

JAMMEH, Kalilu. El viaje de Kalilu. Cuando llegar al paraiso es un infierno. De Gambia a España: $17.345 \mathrm{~km}$ en 18 meses. Barcelona: Plataforma, 2009.

JARRÍN MORÁN, Adriana. La persona en el limbo juridico: aproximación a la situación de los inmigrantes de los centros de internamiento para extranjeros. Dissertaçáo de mestrado - Universitat Autònoma de Barcelona, 2010.

LE MONDE DIPLOMATIQUE. Las migraciones: ¿oportunidad o amenaza? El atlas geopolitico 2010 de Le Monde Diplomatique. Madrid: Le Monde Diplomatique, pp. 7-8, 2010.

LOZARES, Carlos. Valores, campos y capitales sociales. Redes para la Ciencia, (4), pp. 191-196, 2003.

MAUSS, Marcel. El sujeto: la persona. In:__. Sociología y Antropología. Madrid: Tecnos, 1979. pp. 308-330.

MAZKIARAN, Mikel. Inmigración en tiempos de crisis. Bilbao: SOS Racismo, Cuaderno de trabajo (43).

PAJARES, Miguel. Inmigración y mercado de trabajo. Informe 2010. Madrid: Ed. Observatorio Permanente de la Inmigración (OPI) - Ministerio de Trabajo e Inmigración, 2010.

PEDONE, Claudia. Cadenas y redes migratorias, propuesta metodológica para el análisis diacrónico - temporal 
de los procesos migratorios. Empiria: Revista de Metodología de Ciencias Sociales, n.19, enero - junio 2010.

PEREZ-SALES, Pau. Psicología y psiquiatría transcultural: bases prácticas para la acción. Bilbao: Desclée de Brouwer S.A, 2004.

Situación de los Centros de Internamiento para extranjeros en España, Comisión Española de Ayuda al Refugiado (CEAR) en el marco del estudio europeo DEVAS, 2009.

PINYOL, Gemma. Cuando la xenofobia dirige la acción política. Documentos CIDOB, Barcelona, n. 57, 2010.

REHER, David-Sven. Encuesta Nacional de Inmigrantes. Madrid: Universidad Complutense de Madrid [UCM], Grupo de Estudios Población y Sociedad [GEPS], Universidad Nacional de Educación a Distancia [UNED], 2007.

RODRÍGUEZ GARCÍA. Retos y tendencias en la gestión de la inmigración y la diversidad en clave transatlántica. Documentos CIDOB (Migraciones), Barcelona, n. 21, 2010a.

Parentesco transnacional: intersecciones entre las teorías sobre migración y el ámbito procreativo. In: FONS, V., PIELLA, A., VALDÉS, M. Procreación, crianza y género. Aproximaciones antropológicas a la parentalidad. Barcelona: PPU, pp. 117-140, $2010 \mathrm{~b}$.

SAN ROMÁN, Teresa. Los muros de la separación. Ensayo sobre heterofobia y filantropia. Madrid/Bellaterra: Tecnos/Server de Publicacions de la UAB, 1996.

- Sobre la investigación etnográfica. Revista de Antropología Social, v. 18, pp. 235-260, 2009.

STOLCKE, Verena. Europa: nuevas fronteras, nuevas retóricas de exclusión. In: VELLISCA, Oscar (Org.). Extranjeros en el Paraíso. Barcelona: Virus, 1994. pp 235-266.
THAYER, Luis Eduardo. Inmigrantes ecuatorianos en Madrid: la apropiación del espacio y la expropiación del tiempo. Madrid, UCM, 2006.

WEISSENSTEINER, Monika. Torture Evidence on Trial. Missing scars, innocent scars, invisible wounds: Anthropological Reflections on the Documentation of Fear and Violence in European Asylum Procedures. Dissertação de mestrado - National University of Ireland Maynooth, Ireland, 2010.

\section{Páginas web}

Agencia Europea para la gestión de la cooperación operativa en las fronteras exteriores, FRONTEX: http:// www.frontex.europa.eu/ (12/03/2011)

Instituto Nacional de Estadística: http://www.ine.es/ $(18 / 02 / 2011)$

Ministerio de Interior: http://www.mir.es (28/03/2010)

\section{Leyes y normativas}

Naciones Unidas, (1958) Declaración Universal de los Derechos Humanos.

Unión Europea, (2008) Directiva de la Unión Europea relativa a normas y procedimientos comunes en los Estados miembros para el retorno de los nacionales de terceros países en situación irregular.

Ley Orgánica 4/2000 sobre los derechos y libertades de los Extranjeros en España y su integración, (2009), Boletín Oficial del Estado.

\section{autora Adriana Jarrín Morán \\ Doutoranda em Antropologia Social e Cultural / UAB}

Recebido em 11/01/2012

Aprovado para publicação em 01/10/2012 